\title{
REDES SOCIOLÓGICAS DE MERCADO COMO VEÍCULO PARA O FORTALECIMENTO DOS PEQUENOS NEGÓCIOS: O CASO BRASILEIRO DA CACHAÇA
}

Elvis Magno Silva ${ }^{1}$

Valéria G. P. Brito ${ }^{1}$

Olívia Carolina De Resende Ribeiro ${ }^{2}$

${ }^{1}$ Universidade Federal de Lavras

${ }^{2}$ UNIVERSIDADE POSITIVO 


\section{REDES SOCIOLÓGICAS DE MERCADO COMO VEÍCULO PARA O FORTALECIMENTO DOS PEQUENOS NEGÓCIOS: O CASO BRASILEIRO DA CACHAÇA}

Resumo: O objetivo deste trabalho foi apresentar o mercado como uma rede sociológica entre seus diversos empreendimentos e empreendedores, utilizando o mercado da cachaça para exemplificar empiricamente os conceitos teóricos pertinentes ao tema. Esta escolha empírica se justifica uma vez que o mercado recebeu apenas atenção esporádica na sociologia e que os sociólogos só começaram a concentrar sua atenção nos mercados, analisando-os como estruturas sociais concretas, a partir da década de 1980. Neste sentido, este artigo continua com esse renovado interesse sociológico nos mercados, analisando teoricamente a estrutura social de um grande mercado na sociedade capitalista: o mercado da cachaça, o qual se subdivide entre grandes empresas industriais e pequenos empreendedores. Para alcançar este objetivo, recorremos a clássicos como o pai da antropologia francesa Marcel Mauss (MAUSS, 1925; 1950a; 1950b), aos trabalhos seminais da Teoria de Ator-Rede de Michel Callon e Bruno Latour (CALLON, 1998, 2005; e LATOUR, 1994, 2012), bem como trabalhos seminais de especialistas e trabalhos relevantes da atualidade.

Palavras-Chave: Rede Sociológica. Estrutura de Mercado. Plasticidade do Mercado. Mercado da Cachaça.

\section{$1 \quad$ Introdução}

"No fundo, são misturas. Misturam-se as almas nas coisas; misturam-se as coisas nas almas. Misturam-se as vidas e eis como as pessoas e as coisas misturadas saem, cada uma, das suas esferas e se misturam: o que é precisamente o contrato e a troca" (MAUSS, 1950b, p. 81).

Etimologicamente, a palavra "social" vem da raiz sequi (seq-), que é "seguir". Conforme apreciado por Latour (2012), do latim, socius, denota um companheiro, um associado. A genealogia histórica de "social" em diferentes línguas, indica primeiramente "seguir alguém", "alistar" e depois "aliar-se", para então poder denotar "alguma coisa em comum". Outro significado, conforme apresentado por Rousseau (1762), é "ter parte em um empreendimento comercial", que neste caso se trata do "contrato social".

Mas infelizmente, conforme comentado pelo renomado prof. Baker (1984) especialista em sociologia econômica, o mercado recebeu apenas atenção esporádica na sociologia, como nos trabalhos de Weber (1947); Parsons e Smelser (1956). No entanto, os sociólogos começaram a partir da década de 1980, a concentrar sua atenção nos mercados, analisando-os como estruturas sociais concretas, cita-se por exemplo o próprio Baker (1984); Burt (1992); Latour (1994); Callon (1998); Callon (2005); Nenonen et al. (2014); Oliveira e Silva (2016); Pedroza-Gutiérrez e Hernández (2017).

Este artigo continua com esse renovado interesse sociológico nos mercados, analisando a estrutura social de um grande mercado na sociedade capitalista: o mercado da cachaça, uma bebida destilada tipicamente brasileira que se mistura à sua própria história. Desta forma, o objetivo deste trabalho é apresentar o mercado como uma rede sociológica entre seus diversos empreendimentos e empreendedores, utilizando o mercado da cachaça para exemplificar empiricamente os conceitos teóricos pertinentes ao tema. Vale esclarecer que não se pretende

DOI: $10.14211 /$ xi-egepe-118017 
esgotar o assunto, mas contribuir teoricamente com a apreciação e diálogo de rede sociológica aos mercados. Pois como apresentado pela professora Cavalini (2019), a pesquisa teórica pressupõe a discussão e fundamentação da teoria além de dar margem à possíveis contraargumentos e questionamentos acera da legitimação das hipóteses.

Para alcançar o objetivo proposto no trabalho, recorre-se a clássicos como o pai da antropologia francesa Marcel Mauss (MAUSS, 1925; 1950a; 1950b), aos trabalhos seminais da Teoria de Ator-Rede de Michel Callon e Bruno Latour (CALLON, 1998, 2005; e LATOUR, 1994, 2012), bem como a renomados trabalhos na área, como dos professores Burt (1992) e Baker (1984), além de algumas atualidades consultadas na base de dados Scopus e filtrada por relevância, Carneiro (2019), Paiva (2017), Pedroza-Gutiérrez e Hernández (2017), Oliveira e Silva (2016), Braga e Kiyotani (2015), e outros.

Como mencionado por Pedroza-Gutiérrez e Hernández (2017) e adaptado por nós, falar em mercados de bebidas destiladas e mais especificamente da cachaça, não é apenas falar sobre o valor monetário que é realizado nas trocas comerciais, ou da legislação de regulamentação da bebida, ou o volume de produção, mas que tipo de relações sociais permitem desenvolver essas funções, em níveis locais, regionais ou internacionais. É necessário entender como, entre esses grupos, diferentes formas de relações sociais regulam todas as transações, e de que maneira elas interagem para obter certas vantagens. As relações sociais são realizadas com a intenção de assegurar transações de mercado, porque a posse de ativos tangíveis não são as únicas condições necessárias que dão lugar ao comércio da cachaça. É essencial desenvolver os vínculos intangíveis (sociais) para poder usar esses recursos tangíveis, e poder comercializá-los oportunamente, para fazer o mercado fluir ao longo da cadeia de valor.

\section{$2 \quad$ Abordagens de Redes Sociológicas dos Mercados}

O professor Michel Callon, um dos principais expoentes da Escola da Performidade e da Teoria do Ator-Rede, em um de seus trabalhos seminais sobre a performidade, Callon (1998), fez a seguinte pergunta retórica: deveríamos parar por aí e dizer que a análise das redes sociais esgota as questões do pensar e do surgimento dos atores pensantes, descartando a habitual distinção entre situações certas e incertas e, consequentemente, substituindo a noção de informação pela noção de relação nos estudos e práticas do mercado? [adaptado].

A resposta para o autor é "não". Podemos argumentar que desde Marcel Mauss, as ciências sociais foram confrontadas com a tese do dom (dádiva), isto é, a existência de ações desalinhadas e desinteressadas (MAUSS, 1925; 1950a; 1950b). A análise das redes sociais explica o que Mauss acha tão evidente que nem mesmo tenta explicar: a existência de atores pensantes.

Mas como a análise de redes sociais explica a existência do desinteresse a que Mauss concede a maior importância? É examinando mais uma vez esta questão sempre relevante da dádiva e doação desinteressada, que nos permitirá prosseguir, é o que afirma Mauss (1925). Mauss (1950a), por exemplo, mostra como as sociedades não mercantilizadas estabelecem relações de troca pautadas por uma outra lógica que não a mercantil individualista. Nelas, as sociedades primitivas, estabeleceriam tais relações baseadas no que o autor convencionou chamar de princípio da reciprocidade, ou melhor, dádiva. 
Oliveira e Silva (2016) explicam que a dádiva é uma 'troca' recíproca. O vínculo se estabelece através da dádiva devido à tríplice obrigação de dar, receber e retribuir. Entretanto, essa obrigação é um paradoxo, pois para ser eficaz no estabelecimento do vínculo entre doador e receptor, a dádiva deve ser uma atitude espontânea por parte do primeiro. Como dito pelo próprio autor, Mauss $(1950 \mathrm{~b}$, p. 103$)$, "a vida material e moral, a troca, funciona aí sob uma forma desinteressada e obrigatória ao mesmo tempo. Além disso, esta obrigação exprime-se de maneira mítica, imaginária ou, se se quiser, simbólica e coletiva”. Entretanto, isto não quer dizer que seja totalmente isenta de intensões, ao contrário, a dádiva possui o interesse voltado para a reciprocidade de atos de doação gratuita, como dito, "desinteressada e obrigatória" ao mesmo tempo.

Nas atuais sociedades modernas, há a tendência de se desconsiderar as pressuposições da troca-dádiva focadas no vínculo, isto porque se é influenciado pelo nexo mercantil. Quando uma pessoa oferece algo em forma de dádiva, de imediato, a pergunta 'o que você quer em troca?' aparece, causando a disruptura do brilho da dádiva, pois nas trocas mercantis, surgem figuras impessoais e descomprometidas. O ponto central da dádiva é que o principal valor considerado não é a utilidade ou o valor do bem trocado em si, mas sim o valor do vínculo firmado a partir da troca. Ou seja, a dádiva é um processo de circulação de bens simbólicos. Isto significa que o aspecto fundamental não é o bem em si ou o seu valor utilitário, mas como ele representa o valor da relação (OLIVEIRA E SILVA, 2016; VIZEU, 2009).

Sobre o simbólico, Bourdieu (1989) pode auxiliar na compreensão deste fenômeno. Em seu livro O Poder Simbólico, Bourdieu comenta que o poder simbólico é uma forma transfigurada e legitimada das outras formas de poder (econômico, cultural e social), geralmente chamado prestígio, reputação, fama, entre outros sinônimos. Que se trata da forma percebida e reconhecida como legítima das diferentes espécies de capital que perpassam uma relação. $\mathrm{O}$ poder simbólico descreve as relações sociais como relações de força e fazem delas relações de comunicação, na condição de se descreverem as leis de transformação que regem a transmutação das diferentes espécies de capital em capital simbólico e, em especial, o trabalho de dissimulação e de transfiguração que garante uma verdadeira transubstanciação das relações de força, fazendo ignorar ou reconhecer e transformando-as assim em poder simbólico, capaz de produzir efeitos reais.

Logo, o bem utilizado na troca-dádiva, configura a transubstanciação do capital econômico e de status do agente doador da dádiva, bem como seu poder simbólico (vinculo relacional). Mauss (1950b, p. 80) ainda comenta que

Ninguém tem a liberdade de recusar um presente oferecido. Todos, homens e mulheres, tentam ultrapassar-se uns aos outros em generosidade. Havia urna espécie de rivalidade entre quem podia dar a maior quantidade de objetos do maior valor possível.

Desta forma o elemento não-humano passa também a incorporar em si elementos do humano por meio da legitimação da troca-dádiva que manterá o vínculo entre os agentes. E é exatamente esta legitimação (não dita, mas praticada) da troca-dádiva, que confere a transfiguração ao elemento não-humano mencionada por Bourdieu (1989).

Em relação ao não-humano, Callon (2005) comenta que a agência como capacidade de agir e de dar sentido à ação não pode estar contida somente em um ser humano, nem localizada exclusivamente nas instituições, normas, valores e sistemas discursivos ou simbólicos assumidos para produzir efeitos sobre os indivíduos. Para o autor, a ação, 
incluindo sua dimensão reflexiva que produz significado, ocorre em coletivos híbridos que compreendem seres humanos, bem como dispositivos materiais e técnicos, textos, entre outros. Diferentes disciplinas e abordagens têm usado vários conceitos para descrever esses coletivos desde que incorporados à materialidade, como a Teoria de Ator-Rede.

E em se tratando de coletivos, Mauss $(1950 \mathrm{~b}$, p. 55) expõe que são nas economias e nos sistemas legais de direito que não se observam, por assim dizer, simples trocas de bens, de riquezas e de produtos entre os indivíduos em um dado mercado. Mas antes de tudo, "em primeiro lugar, não se trata de indivíduos, trata-se de coletividades que se obrigam mutuamente, trocam e contratam (...)". As pessoas presentes nestes contratos de trocas são pessoas morais, dotadas de sentidos, que se relacionam e se opõem, quer em grupos desafiando-se diretamente, quer por intermédio dos seus representantes.

Além disso, o que elas trocam não são exclusivamente bens e riquezas, móveis e imóveis, bens úteis economicamente. São, antes de mais nada, amabilidades, ritos, serviços, encontros, festas, feiras cujo mercado não é senão um dos seus momentos em que há a circulação das riquezas. Como dito por Mauss (1950b, p. 79-80), "O objetivo é, antes de tudo, moral, o objeto visa produzir um sentimento amigável entre as duas pessoas em jogo, e se a operação não tivesse esse efeito, tudo teria falhado".

Contudo, foi no estudo da Nova Caledónia e mais especificamente dos habitantes das ilhas Trobriand na Melanésia, que Mauss $\left(1950_{\mathrm{b}}\right.$,) encontra de forma mais nítida a noção de moeda por estes povos. E por moeda, ele se refere principalmente a "pulseiras talhadas de conchas", e "colares de madrepérola vermelha" trabalhada por artesãos. Estas moedas de trocas ainda eram pessoais e de valor subjetivo. Eram utilizadas em um sistema de comércio intertribal e intratribal que recebeu o nome de kula. Kula é uma espécie de festa onde líderes de diferentes tribos ou famílias se encontravam e ocorria uma cerimônia (ritual) para se presentear alguns participantes. Os participantes da festa que davam suas "dádivas" eram os que as receberiam na próxima kula. Os que recebiam, eram os que dariam. Os donatários conduziam kula de forma grandiosa, solene, mais elevada possível.

Utilizando as próprias palavras de Mauss (1950b, p. 83-84), o comércio kula é

de ordem nobre. Parece estar reservado aos chefes, sendo estes simultaneamente os chefes das frotas, das canoas, e os comerciantes e também os donatários dos seus vassalos, na espécie dos seus filhos, dos seus cunhados, que são também os seus súbditos, e ao mesmo tempo os chefes de diversas aldeias enfeudadas. Exerce-se de forma nobre, na aparência puramente desinteressada e modesta. Distingue-se cuidadosamente da simples troca econômica de mercadorias (...).

Quando a kula era com menos participantes, os líderes tribais ou familiares podiam combinar de levar produtos para serem comercializados entre eles fora da kula, pois esta "troca comercial" era considerada indigna dentro do kula. Utilizando de suas moedas "pulseiras talhadas de conchas" e/ou "colares de madrepérola vermelha", o viajante solicitava que seu anfitrião preparasse determinado produto para que ele pudesse levar embora por ocasião do retorno. O kula passa então a ser um local onde uma série de outras trocas acontecem. E que, com exceção das grandes expedições solenes, passam a ser um ambiente de trocas prosaicas entre diferentes classes de pessoas. Ocorre desta maneira um livre mercado entre os indivíduos das diferentes tribos e associações (MAUSS, 1950b,).

Sobre o livre mercado, o reconhecido prof. Wayne E. Baker, especialista em sociologia econômica, Baker (1984), comenta que o mercado é uma das instituições mais proeminentes das sociedades capitalistas modernas. Não é apenas o modo predominante de troca 
econômica, mas também um mecanismo importante de integração social. O prof. Baker propõe que os atores do mercado podem ser descritos de forma mais realista por duas suposições comportamentais explicitadas para o estudo da organização econômica: (i) o reconhecimento de que os agentes humanos estão sujeitos à racionalidade limitada e (ii) a suposição de que pelo menos alguns agentes são dados ao oportunismo.

Por racionalidade limitada, entende-se que são as limitações inerentes dos poderes e capacidades cognitivas humanas de transmitir e assimilar informações, analisar dados e tomar decisões sob as condições de complexidade e incerteza. E por oportunismo, à observação de que alguns atores não são inteiramente confiáveis e honestos; em qualquer situação econômica, pelo menos alguns atores tiram proveito de outros, fornecem informações falsas ou enganosas, quebram acordos e assim por diante (BAKER, 1984).

Mas voltando à questão do livre mercado, o emérito prof. Ronald S. Burt, reconhecido por seus trabalhos com redes sociais e capital social, Burt (1992), explica que cada jogador do mercado tem uma rede de contatos, e que a estrutura da rede do jogador e a localização dos contatos na estrutura social proporciona uma vantagem competitiva na obtenção de taxas mais altas de retorno sobre o investimento. Pode-se dizer então, que a rede de contatos é uma descrição da maneira pela qual a estrutura social torna a concorrência imperfeita, criando oportunidades empreendedoras para certos jogadores e não para outros.

Logo, o ator de mercado (jogador) tem um capital social, e o capital social das pessoas agrega-se ao capital social das organizações. Em uma empresa prestadora de serviços, por exemplo, pode haver colaboradores que são reconhecidos por sua capacidade de entregar um produto de qualidade. De maneira mais geral, segundo Burt (1992, p. 9), "propriedades e ativos humanos definem as capacidades de produção da empresa. Relações dentro e além da empresa são capital social”.

Seguindo um caminho inverso deste raciocínio, Pedroza-Gutiérrez e Hernández (2017) realizaram uma investigação empírica no mercado de peixes no México e comentaram que, sobre o mercado e as instituições individuais que fazem parte dele, precisa-se ter em mente que existe a reputação do mercado assim como a reputação de cada atacadista. No entanto, reputações coletivas podem ser transferidas para os indivíduos que são, ou foram, membros dessa rede específica. Além disso, os elementos que servem para construir a reputação de um determinado ator podem, na verdade, ser um reflexo da reputação de grupos, equipes ou organizações em que o ator focal esteve envolvido. Isto porque a vinculação a parceiros de alta qualidade pode melhorar a reputação de uma empresa, especialmente se a empresa for jovem.

Mas independente da abordagem de capital social de Burt (1992) ou da abordagem da racionalidade limitada e oportunismo de Baker (1984), ambos os autores concordam com a noção de que a ação econômica não é realizada por atores individuais, mas está sempre embutida em redes. $\mathrm{O}$ mercado pode tomar forma através da capitalização de oportunidades, enquanto a forma de retenção segue mecanismos indutores de estabilidade que geram confiança entre os atores do mercado. Esta consideração também pode ser verificada em Nenonen et al. (2014).

Em se tratando de redes, o prof. Michel Callon um dos principais expoentes da Teoria de Ator-Rede (juntamente com Bruno Latour), Callon (2005), comenta ainda que a agência (capacidade de agir e de dar sentido à ação por parte dos atores de mercado) não pode estar contida somente em um ser humano nem localizada exclusivamente nas instituições, normas, valores e sistemas discursivos ou simbólicos assumidos para produzir efeitos sobre os 
indivíduos. Para o autor, a ação, inclui sua dimensão reflexiva que produz significado, ocorre em coletivos híbridos que compreendem seres humanos, bem como dispositivos materiais e técnicos, textos, entre outros.

Segundo Latour (1994), o aspecto mais fundamental de nossa cultura é o fato de que vivemos em sociedades que tem por laço social os objetos fabricados. Para o autor, os cientistas sociais deveriam ser capazes de explicar a epidemia dos objetos no coletivo humano, com todas as manipulações e práticas que estes objetos necessitam. E ainda, que "o laço social não se sustenta sem os objetos" (p. 109). Assim como pôde ser visto pela apreciação a pouco sobre kula por Mauss $\left(1950_{\mathrm{b}}\right)$.

Latour (2012, p. 98) ainda esclarece que a sociedade, "constitui o resultado final de um processo e não um reservatório, um estoque ou um capital capaz de fornecer automaticamente uma explicação". Neste sentido, na sociedade, a dominação e poder precisam ser produzidos, feitos, compostos. E o social, "não designa um domínio da realidade ou um item especial; é antes o nome de um movimento, um deslocamento, uma transformação, uma translação, um registro" (p. 99). O autor ainda comenta que o social pode ser melhor entendido através das interações locais. Entretanto, estas interações não são tão fáceis de se perceber, podem ser melhores vistas em sociedades não humanas, como na de formigas, abelhas e macacos. Já nas sociedades humanas, as interações sociais podem ser melhor detectadas se voltarmos os estudos para a noção de força social, uma espécie de recurso para descrever aquilo que já foi aglutinado. Contudo cai-se em um viés de se entender apenas o que já foi (em termos de relações sociais), logo, deve-se substituir esta noção de força social para o que Latour chamou de "interações breves" ou "novas associações". Desde modo, nas interações breves entende-se as relações que já foram e nas novas associações, a que estão sendo ou que serão.

Assim, ao se olhar as habilidades sociais básicas de uma rede, torna-se fácil entender as conexões teciduais existentes. Mas, uma relação de poder que mobilize apenas habilidades sociais estaria limitada a interações muito breves, muito passageiras. Como indicado por Hobbes e Rousseau, nenhum gigante é forte o bastante para não ser dominado durante o sono por um anão. Desta maneira, quando o poder é exercido de forma duradoura, implica que não é feito única e exclusivamente por laços sociais, pois quando se precisa confiar unicamente em laços sociais, não dura muito, é o que afirma Latour (2012).

E é neste sentido que acreditamos que Callon (2005) frisa juntamente com Latour (1994) o papel do não humano (dispositivos materiais e técnicos, textos, entre outros) para o fortalecimento das conexões existentes na rede. São estes dispositivos não-humanos que fortalecem os nós das relações sociais humanas. Como a questão da reciprocidade da dádiva apreciada por Mauss ou a instituição do comércio durante a realização das kulas pelos habitantes das ilhas Trobriand na Melanésia e seus visitantes. De tal modo, é este sentimento de troca, sentimento de reciprocidade, de dever ou de prazer/necessidade pelo bem desejado que contribui para o fortalecimento da rede de relacionamento social entre os diferentes agentes e entre os diferentes atores de forma a privilegiar uma rede sociológica de mercado.

\section{Caracterizando Sociologicamente o Mercado da Cachaça}

Para podermos apreciar o mercado da cachaça de forma sociológica, há a necessidade de um resgate histórico para compreender o movimento social deste mercado ao longo do 
tempo. O recorte histórico se dá do período subsequente a colonização do Brasil (séc. XVI), início da plantação de cana-de-açúcar no país, indo aos dias atuais (séc. XXI).

A versão apresentada pelo historiador Luís da Câmara Cascudo, Cascudo (2014), aponta que a primeira cachaça foi destilada por volta de 1532 em São Vicente, litoral paulista, onde surgiram os primeiros engenhos de açúcar no Brasil (CASCUDO, 2014). Entretanto, há também a versão de que foi na Bahia, em Porto Seguro no ano de 1520, a primeira destilação, pois "pesquisas arqueológicas, conduzidas pela Universidade Federal da Bahia, encontraram ruínas de um engenho de açúcar, datadas de 1520, nas redondezas de Porto Seguro" (IBRAC, 2019).

Apesar de não poder se precisar o local certo da primeira destilaria de cachaça, se pode afirmar que a história da cachaça começa quando os portugueses trouxeram para o Brasil a cana-de-açúcar e as técnicas de destilação utilizadas na Europa. Foi em 1502 que as primeiras mudas da cana chegaram ao Brasil trazidas por Gonçalo Coelho, e que o primeiro engenho de açúcar se deu em Pernambuco, entre os anos de 1516 e 1526, na feitoria de Itamaracá. Sabe-se ainda que logo nas primeiras décadas da presença portuguesa, o número de engenhos no Brasil se multiplicou rapidamente. Estima-se que em 1585 existiam 192 engenhos de açúcar e em 44 anos (1629) esse número subiu para 349 engenhos em atividade (MAPA DA CACHAÇA, 2019).

Desta maneira, o mercado da cachaça em seu início, consistiu-se de produção da bebida pelos produtores de açúcar, os quais aproveitaram do conhecimento de destilação trazidos da Europa para atender apenas seu próprio consumo e da comunidade circunvizinha. Para fins didáticos, apresenta-se esquematicamente a evolução desse mercado por meio das figuras subsequentes.

Figura 1 - Atores que inicialmente compunham o mercado da cachaça

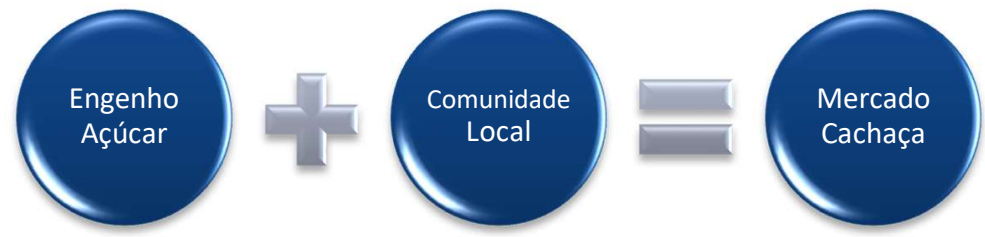

Fonte: Elaborado pelos autores

Conforme mencionado, o número de engenhos de açúcar cresceu rapidamente e com ele a prática da destilação da cana-de-açúcar. Logo, a bebida passa a ser consumida em proporções um pouco mais amplas, regionais. Segundo o Mapa da Cachaça (2019), com a descoberta de ouro em Minas Gerais, os bandeirantes levaram para dentro do continente o destilado de cana em barris de madeira. As explorações para dentro do continente, bem como o gosto pela bebida, proporcionaram que a cachaça passasse a ter uma maior abrangência no contexto nacional. $\mathrm{O}$ aumento do consumo se deu principalmente durante as explorações das Minas Gerais, que devido ao clima mais frio, proporcionou aos colonos se confortarem com uma bebida que os esquentasse, é o que afirma Paiva (2017). Neste sentido, os produtores do engenho de açúcar, aproveitaram-se do oportunismo já mencionado neste artigo por Baker (1984) para expandir o comercio local do engenho para dentro do continente através da abertura proporcionada pela exploração de ouro e outros minérios. Assim, a próxima figura segue acrescida de uma comunidade regional, expandindo a rede inicial de atores deste mercado. 
Figura 2 - Atores que compunham o mercado da cachaça no início de sua expansão
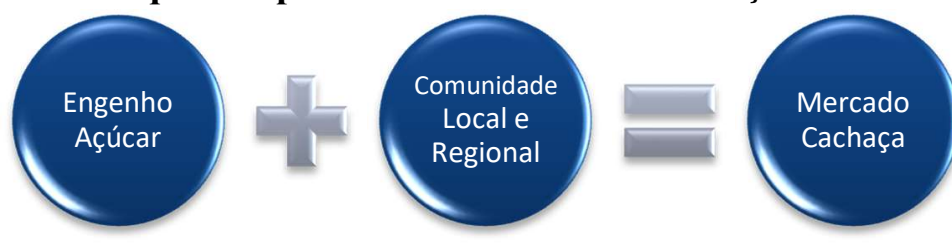

Fonte: Elaborado pelos autores

A Coroa portuguesa acabou enxergando este aumento da produção e do consumo da bebida como uma barreira a outras bebidas alcoólicas de procedência europeia, sobretudo a bagaceira, destilado de origem portuguesa. Braga e Kiyotani $(2015$, p. 259) expõe que a cachaça brasileira estava substituindo a bebida vinda da metrópole, o que significava redução nos lucros da Coroa, e neste sentido a cachaça deveria ser combatida, pois implicava em prejuízo para a economia de Portugal. "A segregação da bebida na sociedade era clara e a perseguição a sua popularização era expressiva, sendo cobrados impostos altos e abusivos por sua fabricação e consumo, na tentativa de atrapalhar o aumento da produção". Devido a esta racionalidade limitada do governo português, relembramos o que já foi apontado no artigo por Burt (1992) que aprecia que o mercado pode reter sua forma através de mecanismos indutores de estabilidade, aos quais podem gerar confiança entre os diferentes atores do mercado. Neste caso, o aparecimento então de um novo ator neste ressente mercado da cachaça, o Estado, o qual se relaciona com os produtores e comerciantes por intermédio de seus agentes representantes.

Figura 3 - Atores que compunham o mercado da cachaça meados Séc. XVI
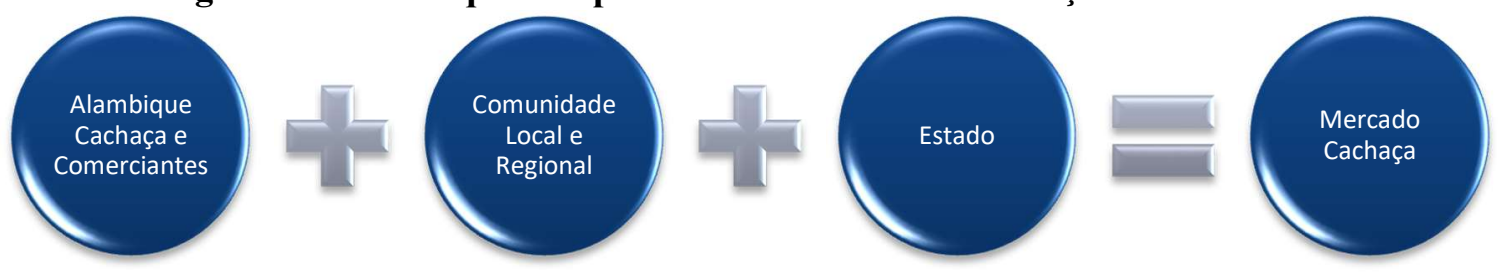

Fonte: Elaborado pelos autores

Foi em 1635 que como consequência, a venda da cachaça foi proibida na Capitania da Bahia, e entre 1639 até as últimas décadas do século XVIII o governo português tomou diversas medidas na tentativa de impedir sua produção no Brasil. Dias (2014) comenta que entre novembro de 1660 e abril de 1661 ocorreu no Rio de Janeiro a chamada "Revolta da Cachaça". Tal revolta tinha como motivador a desistência do governador Salvador de Sá do acordo que legalizaria a produção e comércio da cachaça através do pagamento de impostos pelos senhores de engenho. Na Revolta da Cachaça, cento e doze senhores de engenho não aceitaram a proibição da fabricação e comércio da bebida, e como resultado, os senhores de engenho conseguiram que o governador fosse deposto e a proibição fosse cancelada. Produtores e comerciantes se associaram e cooperaram para o fim do embargo da produção e comercialização da cachaça. Este foi um marco que possibilitou a criação posterior de associações e cooperativas de produtores de cachaça. Foi nesse sentido que Pedroza-Gutiérrez e Hernández (2017) expuseram que reputações coletivas podem ser transferidas para indivíduos e que são ou foram membros de uma rede específica. E que os elementos que 
servem para construir a reputação de um determinado ator podem, na verdade, ser um reflexo da reputação de grupos, equipes ou organizações em que o ator focal esteve envolvido. Neste contexto da Revolta da Cachaça é que os produtores e comerciantes se unem para formação de agremiações para reivindicar a queda do governador e a liberação do comercio da bebida. Tendo como consequência a nomeação de outro governador que estivesse alinhado com seus interesses, bem como a "descoberta" de sua força política frente ao Estado, alimentando assim um capital simbólico, um poder simbólico (BOURDIEU, 1989) o qual ganha forças em décadas subsequentes levando posteriormente a colônia brasileira a proclamar independência da coroa portuguesa.

Figura 4 - Atores que compunham o mercado da cachaça Séc. XVII

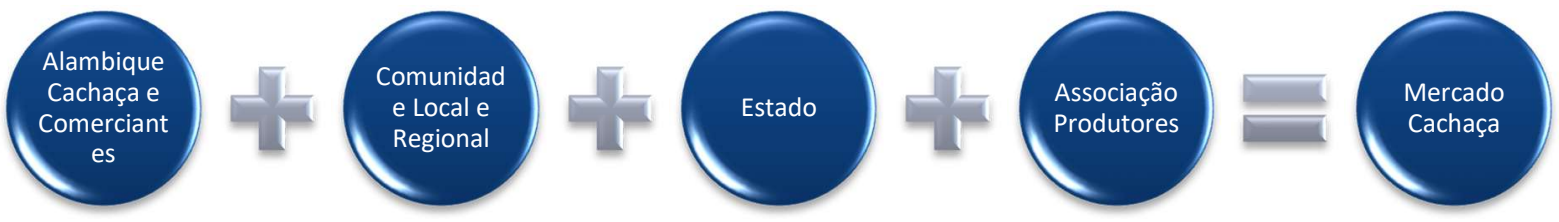

Fonte: Elaborado pelos autores

Mas foi somente a partir de 1922, cem anos após a proclamação da independência, com a Semana de Arte Moderna, que ocorreu um movimento de renovação da brasilidade e da valorização da cultura nacional, a qual foi realizada por intelectuais, artistas e estudiosos, permitindo que a cachaça se tornasse novamente uma bebida relevante econômica e culturalmente, consolidando-se como um símbolo da identidade brasileira (DIAS, 2014). Carneiro (2019) complementa que nesse evento (Semana de Arte Moderna), estavam presentes os grandes nomes das nossas artes, como Tarsila do Amaral, Vila Lobos, Di Cavalcanti, Mário de Andrade, e que o próprio Mário de Andrade apresentou uma obra chamada "Eufemismos da Cachaça". Nesse evento, foi proibido servir outra bebida que não fosse cachaça. Esse ato vai ao encontro do que foi mencionado por Latour (1994) de que o aspecto mais fundamental de nossa cultura é o fato de que vivemos em sociedades que tem por laço social os objetos fabricados, que neste caso, na Semana de Arte Moderna, o laço social foi materializado na cachaça, bebida tipicamente e genuinamente brasileira (GERK et al., 2019).

Mas foi pelos anos 1940 e 1950, com o fim dos engenhos de açúcar mascavo, que foram obrigados a fechar por conta das emergentes usinas de açúcar refinado branco em larga escala, que várias propriedades tiveram que fechar e os sobreviventes tiveram que se reinventar no mercado da produção na cachaça. Carneiro (2019) ainda comenta que a

grande virada só começou mesmo por volta de 1995, 1996, onde, por pressão de produtores e por vontade política, o Governo de Fernando Henrique Cardoso começou a produzir as primeiras portarias e instruções normativas sobre a cachaça. Só então é que foram definidas as regulamentações técnicas de fabricação, os procedimentos de registro de produtores, a classificação e rotulagem e os processos de fiscalização.

E foi exatamente nesta virada de 1995 para 1996 que as grandes indústrias começam a despontar, promovendo uma significativa mudança no mercado da cachaça. Promovendo o fechamento de diversos engenhos de açúcar por todo o país. Entretanto, alguns produtores se reinventaram através da criação de associações e representações de classe especialmente destinadas a agregar valor ao pequeno produtor por intermédio principalmente da cachaça de 
alambique envelhecidas, premium e extra premium. Desta forma o mercado apresenta uma nova dinâmica, de um lado os grandes produtores industriais com o método de destilação por coluna e de outro lado os pequenos produtores artesanais com o método de destilação por alambique. Paiva (2017) ainda comenta que este modo de produção artesanal (alambique) envolve práticas que preservaram saberes e costumes tradicionais tais como a separação (cabeça, coração e calda) que datam do período colonial. O uso do alambique de cobre simboliza o cuidado, a qualidade, a diferenciação da produção industrial em larga escala, e a proteção e preocupação com a saúde do consumidor, em contraste com a produção industrial a qual é vinculada apenas ao ganho econômico.

Em ambos os seguimentos, a produção passa a um novo patamar, a profissionalização da cadeia produtiva, melhorando a qualidade da bebida e proporcionando maior eficiência dos processos tanto na produção industrial quanto na produção artesanal. Há também um trabalho na melhora da imagem da bebida, com mudanças nas embalagens, rótulos e garrafas, tornando-a mais sofisticada. Ocorre ainda o envolvimento de universidades e fundações de pesquisa as quais têm utilizado este mercado e seus atores como objetos de estudo, promovendo ainda mais os avanços para o setor. Como o caso da Universidade Federal de Lavras que desenvolveu quatro tipos de leveduras que proporcionam maior eficiência na conversão de açúcar em álcool durante a fermentação do mosto da cana-de-açúcar para produção da cachaça (ALVES 2014).

Desta forma, a configuração da rede de relações do mercado de cachaça pode ser representada da seguinte forma:

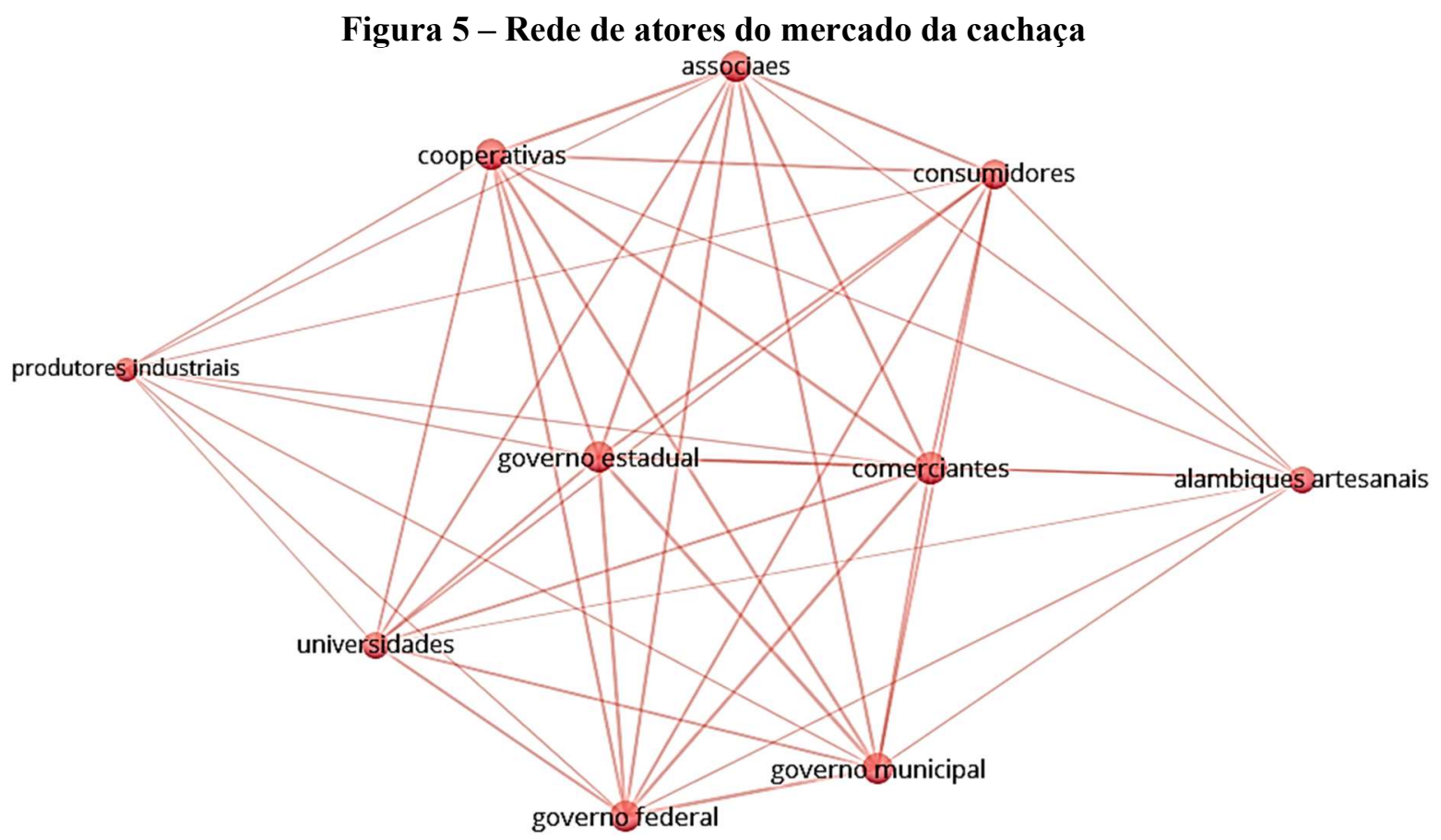

Fonte: Elaborado pelos autores

De forma genérica, os atores podem ser identificados como: alambiques artesanais, produtores industriais, consumidores, comerciantes, universidades, associações, cooperativas, governo federal, governo estadual e governo municipal. Pode ser identificado inicialmente 
neste mercado da cachaça, pela análise feita pelo software VOSviewer, a configuração dos dois seguimentos já mencionados no trabalho (clusters). O primeiro cluster de produtores industriais (Figura 6) e o segundo cluster de alambiques artesanais (Figura 7):

\section{Figura 6 - Clusters industrial da rede de atores do mercado da cachaça}

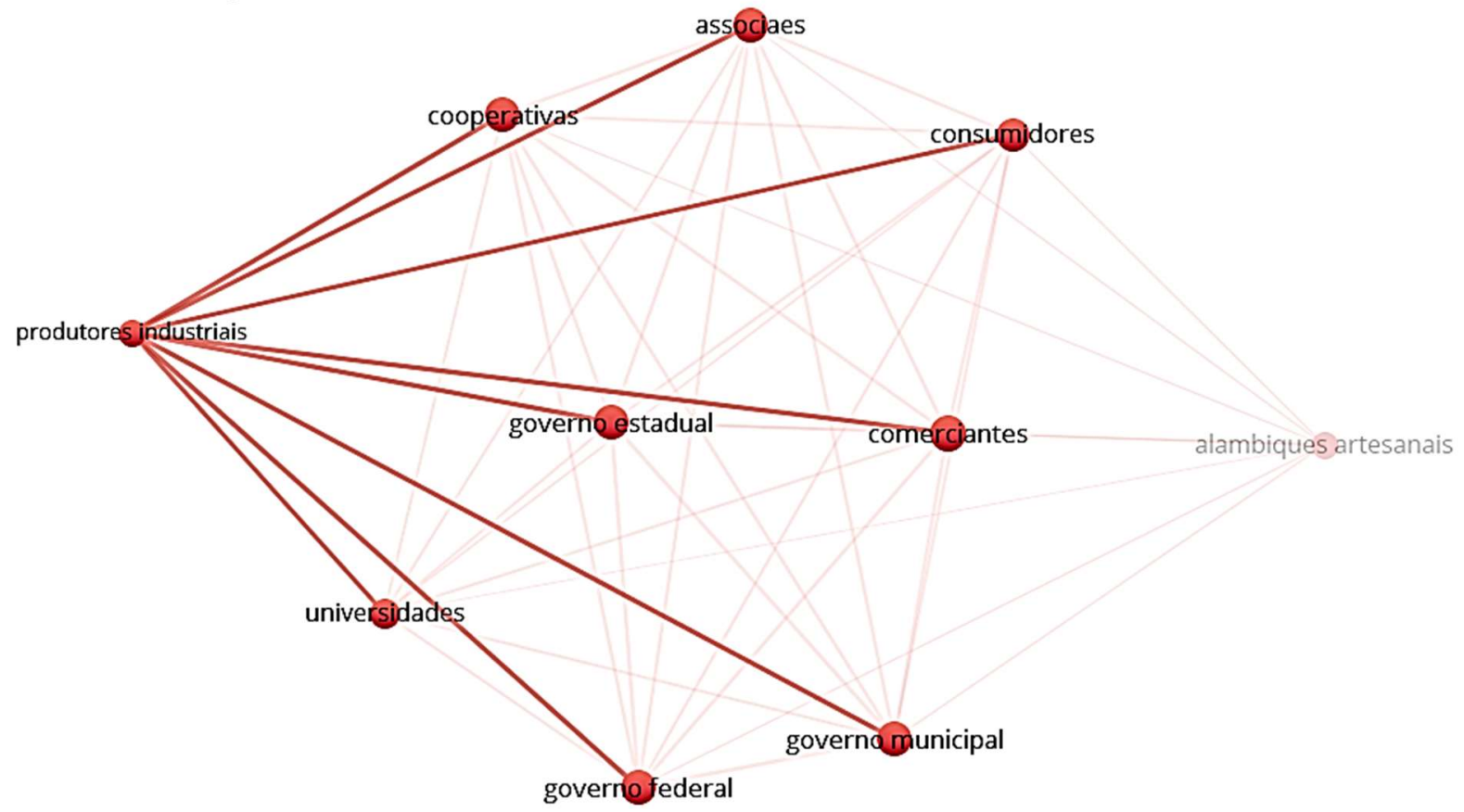

Fonte: Elaborado pelos autores

Figura 7 - Clusters artesanal da rede de atores do mercado da cachaça

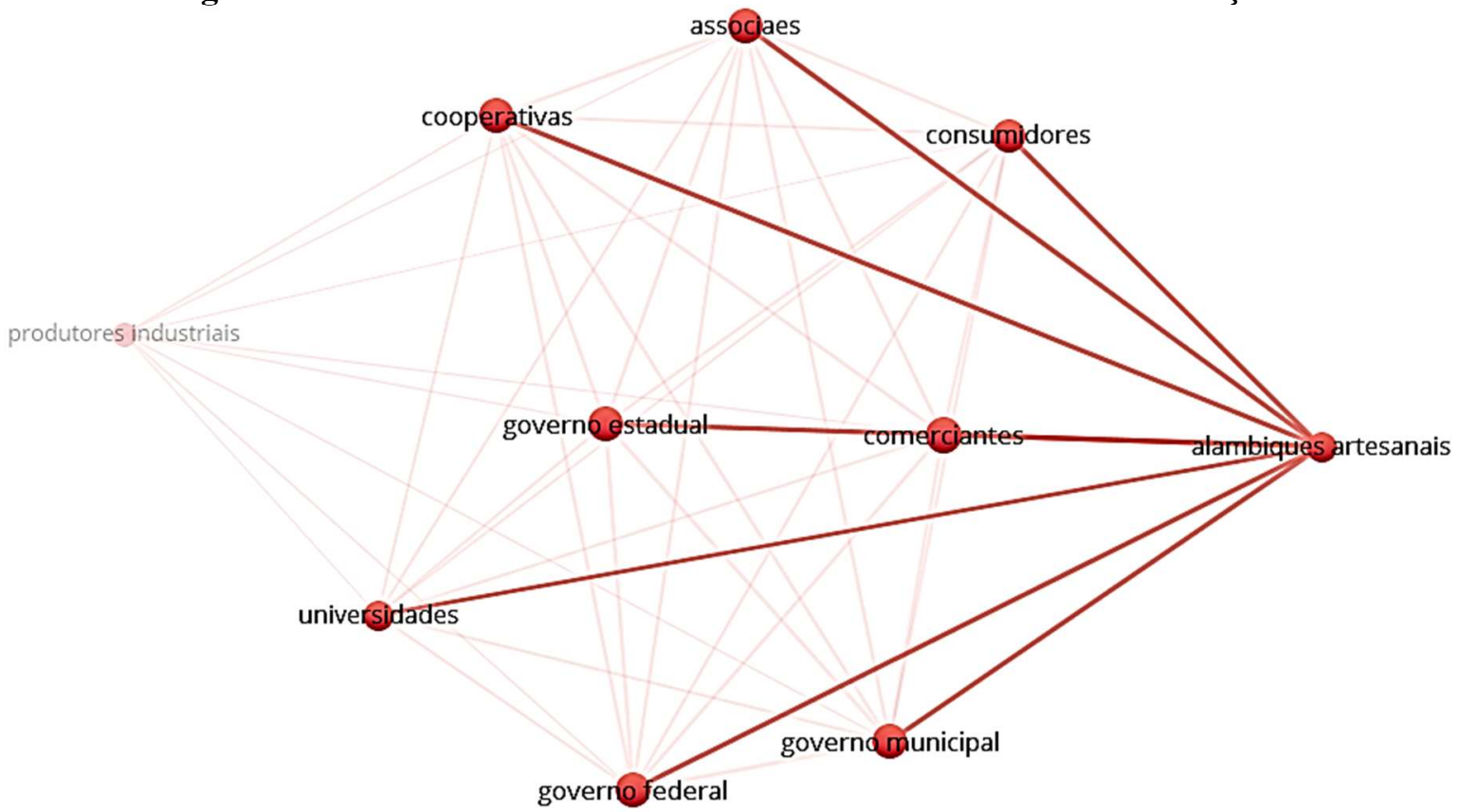

Fonte: Elaborado pelos autores 
Segundo a Expo Cachaça (2019), são 600 mil empregos gerados de forma direta e indireta em ambos (industrial e artesanal), isto sem considerar o mercado informal que ainda é elevado em algumas regiões do país. Ao todo são 7,5 bilhões de reais de movimentação anual em sua cadeia produtiva. No mercado nacional, a cachaça corresponde a $87 \%$ do market share dos destilados do Brasil, com cerca de 30.000 produtores, sendo que destes, $98 \%$ são de pequeno porte ou microempresários. Destaque-se que $70 \%$ da produção nacional é de cachaça industrial (de coluna) e 30\% de cachaça de alambique.

Seguindo a referência de Pedroza-Gutiérrez e Hernández (2017), o mercado da cachaça é composto por um grupo de empresas, uma aliança estratégica, onde as empresas são atraídas pela reputação do mercado para ter acesso a novos recursos valiosos dos parceiros (como cooperativa associações). Do ponto de vista de empresas jovens e empreendedoras, a afiliação a parceiros de aliança já estabelecidos (empresas maiores ou mais antigas) pode fornecer uma variedade de benefícios, como acesso preferencial a recursos valiosos ou efeitos indiretos da reputação do parceiro.

No caso dos atacadistas da cadeia de suprimentos (retratado na rede com o nó "comerciantes"), é conveniente que eles estabeleçam alianças com fornecedores com uma reputação positiva, porque isso significa ganhar vantagem competitiva. Além disso, uma empresa bem reputada influenciará positivamente a tomada de decisões do consumidor e fará com que seus parceiros desejem desenvolver uma relação próxima com ela. Assim por exemplo, a reputação de um alambique artesanal em geral atrai associações, cooperativas e compradores, e cada empresa pertencente a esse grupo tem que manter sua reputação individual para fazer parte da aliança e ter retornos positivos.

Considerando a racionalidade limitada mencionada por Baker (1984), pode-se exemplificar com a falta de conhecimento técnico-específico como, por exemplo, no manejo da cana-de-açúcar; na utilização de leveduras para fermentação ou no envelhecimento, levando os produtores, principalmente os artesanais, a procurarem informações em universidades e institutos de pesquisa com o intuito de minimizar este postulado de racionalidade limitada. A busca por melhores práticas, tornando o negócio mais eficiente e sofisticado, é percebido neste mercado da caçada. Ressalte-se como exemplo o uso da levedura a UFLA-CA11 da Universidade Federal de Lavras que já está sendo comercializada. Esta levedura acelera o processo de fermentação e produz mais cachaça a partir da mesma quantidade de cana, como comentado por Alves (2014).

Esta busca por conhecimento, seja por intermédio de universidades ou institutos, promove o aumento e fortalecimento da rede de relações do mercado. Outra fonte de informações são os cursos e encontros promovidos por associações. Cite-se por exemplo a ANPAQ (Associação Nacional dos Produtores e Integrantes da Cadeia Produtiva e de Valor da Cachaça de Alambique) que oferece regularmente cursos de Mestre Alambiqueiro, cursos de Blend, Padronização e Análise Sensorial, entre outros. Há duas categorias de associados na ANPAQ: os "produtores" e os "fornecedores e prestadores de serviço". Seus encontros e cursos também são abertos para pesquisadores e interessados em conhecer este mercado da cachaça. Neste sentido, várias relações sociais são criadas, mantidas e fortalecidas com os encontros e cursos. Há trocas de experiências, reivindicações da classe e momentos sociais, os quais promovem a interação social.

Outro encontro muito expressivo é o promovido pela Expo Cachaça, que é tida como "a maior e mais importante e conceituada vitrine mundial da cadeia produtiva e de valor da cachaça, no formato consagrado B2B-FEIRA e B2C-FESTIVAL" (EXPO CACHAÇA, 
2019). B2B (business to business) em que o foco são os relacionamentos entre empresas e o $\mathrm{B} 2 \mathrm{C}$ (business to consumer) que prioriza o contato com o consumidor final, o cliente pessoa física. Além da feira em si com a exposição em estandes pelos participantes, há também palestras e oficinas com conteúdo técnicos e shows e gastronomia para o entretenimento do público. Em um sentido mais amplo, é pertinente a comparação da Expo Cachaça com a antiga cerimônia do kula, pois ocorrem doação de brindes pelos expositores, degustação, shows, bem como a comercialização de mercadorias e fechamento de parcerias.

Por fim, ainda revelando as relações da rede sociológica do mercado da cachaça, destacamos o business to business entre as grandes indústrias que compram a produção das cooperativas e os pequenos produtores que vendem para estas mesmas cooperativas. Pode ser mencionado como exemplo, a COPACESP (Cooperativa dos Produtores de Cana, Aguardente, Açúcar e Álcool do Estado de São Paulo) que tem em sua lista de clientes a maior produtora de cachaça do Brasil, a Companhia Müller de Bebidas, também conhecida pelo seu tradicional produto, a Cachaça 51. Paula Videira, gerente de marketing do conglomerado da Cachaça 51, em entrevista a Godoy (2017) disse que o conglomerado coloca no mercado cerca de 200 milhões de litros de cachaça, somando o mercado nacional e internacional. E que este volume de produção corresponde a $40 \%$ de toda a cachaça destilada no Brasil.

Ainda na relação business to business, o Mapa da Cachaça (2015) comenta que o pequeno produtor chega a receber das cooperativas, de $\mathrm{R} \$ 1,00$ a $\mathrm{R} \$ 2,00$ por litro da cachaça prata (pura, sem envelhecimento). Estes preços são praticados, a pelo menos desde 2007, segundo a Agência Sebrae de Notícias (2007). E que a variação de preço depende da safra, que por sua vez fica à mercê do clima, principalmente das chuvas. Neste sentido, os pequenos produtores podem ser ver em alguns casos "com as mãos amarradas" devido à falta de poder de barganha ou por não negociarem diretamente com as grandes indústrias do seguimento que preferem as cooperativas devido ao grande volume ofertado, por exemplo, a COPACESP que possuí uma capacidade de armazenamento para 36 milhões de litros de álcool (COPACESP, 2019). Desta forma, pode ser caracterizado a ação oportunista destacada pelo professor Baker (1984) em sua obra e mencionado anteriormente neste artigo.

\section{Considerações Finais}

O objetivo deste artigo foi apresentar o mercado como uma rede sociológica entre seus diversos empreendimentos e empreendedores, utilizando o mercado da cachaça para exemplificar empiricamente os conceitos teóricos pertinentes ao tema. Como mencionado em nossa introdução, não foi intenção esgotar o assunto, mas poder contribuir com a apreciação e diálogo para a construção de uma rede sociológica aos mercados.

Foi apreciado no trabalho que as relações sociais são realizadas com a intenção de assegurar transações de mercado, porque a posse de ativos tangíveis não são as únicas condições necessárias que dão lugar ao comércio da cachaça. É essencial desenvolver os vínculos intangíveis (sociais) para poder usar esses recursos tangíveis, e poder comercializálos oportunamente, para fazer o mercado fluir ao longo da cadeia de valor.

Foi visto também que a agência como capacidade de agir e de dar sentido à ação não pode estar contida somente em um ser humano, um empreendedor, nem localizada exclusivamente nas instituições, normas, valores e sistemas discursivos ou simbólicos 
assumidos para produzir efeitos sobre os indivíduos. O poder simbólico descreve as relações sociais como relações de força e fazem delas relações de comunicação capaz de produzir efeitos reais.

Destacamos ainda que, para os autores desta abordagem sociológica ao mercado, existe a noção de que a ação econômica não é realizada por atores individuais, mas está sempre embutida em redes. $\mathrm{O}$ mercado pode tomar forma através da capitalização de oportunidades, enquanto a forma de retenção segue mecanismos indutores de estabilidade que geram confiança entre os atores do mercado. Assim, ao se olhar as habilidades sociais básicas de uma rede, torna-se mais fácil entender as conexões teciduais existentes.

Ao final do trabalho, acreditamos ter alcançado o objetivo proposto. Deixamos como sugestão para trabalhos futuros, estudar, à luz da Teoria das Práticas, as diversas relações sociais existentes em um alambique de cachaça ou em uma cooperativa.

\section{$5 \quad$ Referências}

AGÊNCIA SEBRAE DE NOTÍCIAS. (2007). Cooperativa lança cachaça em Minas Gerais. Disponível em <http://www.mg.agenciasebrae.com.br/sites/asn/uf/MG/cooperativalanca-cachaca-em-minas-gerais,cb195f6a2d136410VgnVCM1000003b74010aRCRD>.

Acesso em: 02 ago. 2019.

ALVES, M. de C. Pesquisa e novos negócios na redescoberta desse aguardente secular. In: Ciência e Cultura, vol. 66, nr 2, p. 60-61, 2014.

BAKER, W. E. The social structure of a national securities market. In: American Journal of Sociology, vol. 89, nr 4, p. 775-811, 1984.

BOURDIEU, Pierre. O poder simbólico. Rio de Janeiro: Ed. Bertrand BR S.A., 1989.

BRAGA, M. V. F.; KIYOTANI, I. B. A cachaça como patrimônio: turismo cultura e sabor. In: Revista de Turismo Contemporâneo, vol. 3, nr 2, p. 254-275, 2015.

BURT, R. S. Structural holes: the social structure of competition. Cambridge, MA: Harvard University Press, 1992.

CALLON, M. Introduction: the embeddedness of economic markets. In: CALLON, M. (Ed.). The laws of the market. Oxford: Basil Blackwell, 1998.

CALLON, M. Why virtualism paves the way to political impotence: A reply to Daniel Miller's critique of" The laws of the market". In: Economic Sociology: European electronic newsletter, vol. 6, nr 2, p. 3-20, 2005.

CALLON, M. Why virtualism paves the way to political impotence: A reply to Daniel Miller's critique of" The laws of the market". In: Economic Sociology: European electronic newsletter, vol. 6, nr 2, p. 3-20, 2005.

CARNEIRO, Maurício. (2019). Cachaça: breve história da ascensão do destilado nacional. In: Jornal da Paraíba [online]. Disponível em: $<$ http://blogs.jornaldaparaiba.com.br/ confrariadocopo/2019/05/21/cachaca-breve-historia-daascensao-do-destilado-nacional/>. Acesso 15 ago. 2019.

CASCUDO, Luís da Câmara. Prelúdio da cachaça. São Paulo: Global Editora, 2014.

CAVALIINI, Marcela. Pesquisa teórica e pesquisa empírica. Disponível em $<$ http://www.midia.uff.br/metodologia/?p=169694>. Acesso em: 17 out. 2019.

COPACESP. Serviços prestados. Disponível em: <http://copacesp.com.br/servicosprestados/>. Acesso em 25 ago. 2019.

DIAS, N. C. A Cachaça é nossa: cultura e ideologia na construção da identidade nacional. Anais Brasileiros de Estudos Turísticos: ABET, v. 4, n. 1, p. 35-44, 2014. 
EXPO CACHAÇA. Números da cachaça: a importância do mercado da cachaça no Brasil e no mundo. (2018). Disponível em $<$ http://www.expocachaca.com.br/numeros-dacachaca/>. Acesso em: 24 jul. 2019.

GERK, A. de O.; MÜlLER, C. V.; MARCUSSO, E. F. A cachaça no brasil: dados de registro de cachaças e aguardentes. Ministério da Agricultura, Pecuária e Abastecimento MAPA, Brasília, 2019.

GODOY, Denyse. (2017) Cachaça 51 tem versão envelhecida em barril de uísque dos EUA a RS 250. Disponível em $<$ https://economia.uol.com.br/noticias/ redacao/2017/04/18/cachaca-51-tem-versao-envelhecida-em-barril-de-uisque-dos-eua-custa-r250.htm>. Acesso em: 04 ago. 2019.

IBRAC. Instituto Brasileiro da Cachaça. Um pouco de história. (2011). Disponível em: $<$ http://www. ibrac.net/index.php/ig-cachaca/historia-da-cachaca >. Acesso em: 24 jul. 2019.

LATOUR, B. Jamais fomos modernos: ensaio sobre antropologia simétrica. Rio de Janeiro: Ed. 34, 1994.

LATOUR, B. Reagregando o social: uma introdução à Teoria do Ator-Rede. Salvador: EDUFBA, 2012.

MAPA DA CACHAÇA. (2015). Devemos falar sobre os produtores informais da cachaça artesanal? Disponível em <https://www.mapadacachaca.com.br/artigos/devemosfalar-sobre-os-produtores-informais-de-cachaca/>. Acesso em: 02 ago. 2019.

MAPA DA CACHAÇA. A história da cachaça. (2011). Disponível em <https://www. mapadacachaca.com.br/artigos/historia-da-cachaca/>. Acesso em: 24 jul. 2019.

MAUSS, M. [1925]. The gift: forms and functions of exchange in archaic societies. London: Cohen and West, 1966.

MAUSS, M. [1950a]. The gift: forms and reason for exchange in archaic societies. London and New York: Routledge, 2002.

MAUSS, M. [1950b]. Ensaio sobre a dádiva. Lisboa: Edições 70, 2001.

NENONEN, Suvi; KJELLBERG, Hans; et al. A new perspective on market dynamics: market plasticity and the stability-fluidity dialectics. In: Marketing Theory, vol. 14, $\mathrm{nr} 3$, p. 269-289, 2014.

OLIVEIRA, D. H.; SILVA, E. M. Reciprocidade da sociologia da dádiva frente à epistemologia adotada pelo pesquisador. In: Convibra [anais..], 2016. Disponível em: $<$ http://www.convibra.com.br/upload/paper/2016/31/2016_31_13070.pdf >. Acesso em: 08 ago. 2019.

PAIVA, A. L. de. Lógicas Institucionais e Estratégia como Prática: um estudo em organizações constitutivas do campo da cachaça de alambique. 2017. 229 f. Dissertação (Mestrado) - Universidade Federal de Lavras, Programa de Pós-Graduação em Administração, Lavras, 2017.

PARSONS, Talcott; SMELSER, Neil J. Economy and society. New York: Free Press, 1956. Disponível em <https://books.google.com.br/books?id=sGAJUlxYniMC\&hl=pt-BR>. Acesso em: 19 ago. 209.

PEDROZA-GUTIÉRREZ, C.; HERNÁNDEZ, J. M. Social networks, market transactions, and reputation as a central resource: the Mercado del Mar, a fish market in central Mexico. In: Plos One, https://doi.org/10.1371/journal.pone.0186063, October 2017.

ROUSSEAU, Jean Jacques. (1762). Do contrato social. 3. ed. São Paulo: Martin Claret, 2010. 
VIZEU, F. Contribuições da sociologia da dádiva aos estudos sobre organizações substantivas. In: O\&S - Revista Organizações e Sociedade, vol. 16, nr 50, p. 409 - 427, Jul/Set, 2009.

WEBER, Max. The Theory of Social and Economic Organization. Translated by A. M. Henderson and Talcott Parsons. New York: Free Press, 1947. 